Synthesis of Natural

Products and

Potential Drugs

\section{Total Synthesis of Zaragozic Acid C}<smiles>COCC1OC(=O)[C@H](O[Na])[C@H](O[Na])[C@H]1O[Na]</smiles>

A<smiles>CC(Cc1ccccc1)C(CCCI)O[Pb]</smiles>

1. B, $t$-BuLi, hexane- $\mathrm{Et}_{2} \mathrm{O}(4: 1)$ -78 to $0^{\circ} \mathrm{C}$, then $\mathrm{MeOH}$ $\mathrm{MeSO}_{3} \mathrm{H},-78^{\circ} \mathrm{C}$ to r.t. 2. $\mathrm{PhCH}(\mathrm{OMe})_{2}, \mathrm{CSA}, \mathrm{MeCN}, 0^{\circ} \mathrm{C} \mathrm{OBn}$ 3. $\mathrm{BzCl}, \mathrm{DMAP}$, py

4. $\mathrm{NaBH}_{3} \mathrm{CN}, \mathrm{HCl}, \mathrm{THF}, 0^{\circ} \mathrm{C}$

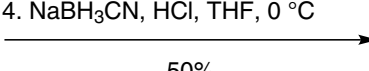
$50 \%$

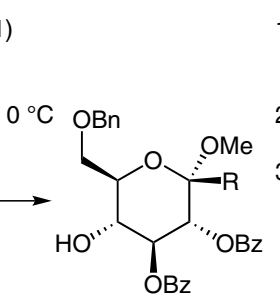
C
1. D $(5 \mathrm{~mol} \%), \mathrm{KBr}$ $\mathrm{NaOCl}$, aq $\mathrm{NaHCO}_{3}$ $\mathrm{CH}_{2} \mathrm{Cl}_{2}(1: 1)$

2. $\mathrm{E}, n$-BuLi, hexane- $\mathrm{Et}_{2} \mathrm{O}$ $(5: 1),-78$ to $0^{\circ} \mathrm{C}$

3. $\mathrm{BzCl}$, py

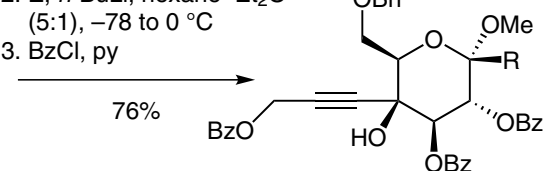<smiles>ON1CC2CC3CC(C2)C31</smiles><smiles>C#CCOC</smiles>

1. TMSOTf, py, $\mathrm{CH}_{2} \mathrm{Cl}_{2}$

2. $\mathrm{RuO}_{2} \cdot \mathrm{H}_{2} \mathrm{O}$ ( 0.3 equiv) $\mathrm{NalO}_{4}, \mathrm{MeCN}^{-\mathrm{CCl}_{4}-\mathrm{H}_{2} \mathrm{O}} 62 \%$ $(1: 1: 1.5)$

\section{Key words}

squalene synthase inhibitor

Norrish-Yang

cyclization

squalestatins

zaragozic acid C

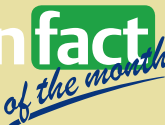

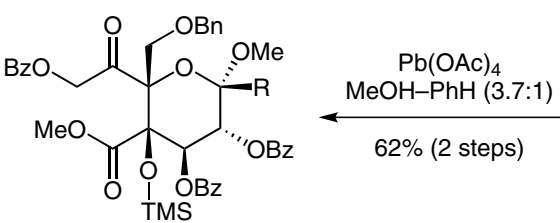

I

$$
\begin{aligned}
& \text { 1. LAH, Lil, Et } \mathrm{Et}_{2} \mathrm{O},-78^{\circ} \mathrm{C} \\
& 49 \% \text { 3. D ( } 0.2 \text { equiv), } \mathrm{NaClO}_{2}, \mathrm{NaOC} \\
& \text { MeCN-pH } 7 \text { buffer (4:3) } \\
& \text { 4. } \mathrm{TMSCHN}_{2}, \mathrm{MeOH}-\mathrm{PhH}(1: 1)
\end{aligned}
$$

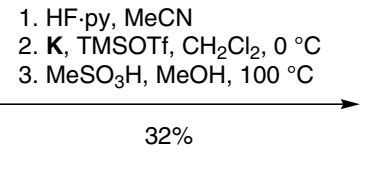

2. K, TMSOTf, $\mathrm{CH}_{2} \mathrm{Cl}_{2}, 0^{\circ} \mathrm{C}$ 3. $\mathrm{MeSO}_{3} \mathrm{H}, \mathrm{MeOH}, 100^{\circ} \mathrm{C}$

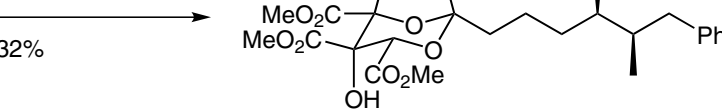

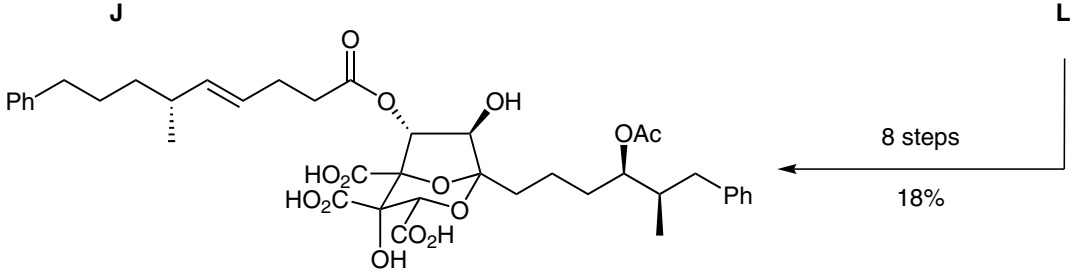

Zaragozic Acid C

Significance: Zaragozic acid $\mathrm{C}$ is an inhibitor of mammalian squalene synthase. The family of zaragozic acids has recently regained attention due to further biological activities, e.g. as antitumor agents or as inhibitors of Ras farnesyl protein transferase and dengue virus replication.

SYNFACTS Contributors: Erick M. Carreira, Philipp Sondermann Synfacts 2017, 13(04), 0337 Published online: 17.03.2017 Dol: 10.1055/s-0036-1590102; Reg-No.: C01117SF
Comment: Gluconolactone-derived A was concisely elaborated into diketone $\mathbf{G}$. An acylative sequence of a Norrish-Yang cyclization and oxidative cleavage yielded I. Acid-catalyzed rearrangement revealed the characteristic highly oxygenated bicyclic core that was further transformed into zaragozic acid $\mathrm{C}$. 